\title{
Variability in content of hydrophilic extractives and individual phenolic compounds in black locust stem
}

\author{
Viljem Vek ${ }^{1}$, Ida Poljanšek ${ }^{1}$ and Primož Oven ${ }^{1}$ \\ ${ }^{1}$ Department of Wood Science and Technology \\ University of Ljubljana, Biotechnical Faculty \\ Jamnikarjeva 101, 1000, Ljubljana, Slovenia
}

\begin{abstract}
The main goal of this study was to investigate the amounts of hydrophilic extractives in bark and wood samples of black locust stem (Robinia pseudoacacia L.). The concentrations of extractives were highest in the outermost samples of heartwood. Knotwood of black locust contained less DHR than heartwood. Significantly less hydrophilic compounds were extracted from bark and sapwood samples. This study shows that heartwood of black locust can be considered a source of value-adding compounds. The investigation showed significant variability in the content of extractives in a radial direction and less pronounced axial variability within the black locust stems.
\end{abstract}

\section{INTRODUCTION}

Black locust (Robinia pseudoacacia L.) heartwood is characterized by high resistance against fungi and insects and high natural durability, even when in water (Sachsse 1984; Scheffer and Morrell 1998). Black locust wood is therefore used in various external applications, such as shipbuilding, masts, mining timber and vineyards (Bostyn et al. 2018; Torelli 2003; Vítková et al. 2017). Despite the spread of this wood species in Europe (Vítková et al. 2017) and relatively broad applicability of its wood (Sachsse 1984; Torelli 2003), understanding of the content and distribution of extractives within a black locust tree remains surprisingly fragmentary.

A literature review revealed that either only axial or only radial variability in the content of extractives within a black locust tree has received attention. There has been no integral study showing not only the content of groups of extractives but data on the content of individual compounds within the tree. The distribution of characteristic phenolic compounds in the radial direction of the stem at different times in a season was provided by Magel et al. $(1994 ; 1991)$ when studying heartwood formation in black locust. It was demonstrated that that the extractive fraction soluble in a methanol/water solvent was higher in mature heartwood than in juvenile heartwood, but data on the content of individual compounds are not given (Dünisch et al. 2010; Latorraca et al. 2011). Axial variation of extractives within trees has been demonstrated with data on the fraction extracted with dichloromethane and the fraction obtained after extracting wood with hot water, but variation in the content of individual compounds was not shown. The content of hot-water extractives increased in heartwood but decreased in sapwood from the bottom to the top of the stems, while the reverse occurred for the dichloromethane extractive content of sapwood (Adamopoulos et al. 2005).

The aim of the investigation was qualitative and quantitative analysis of hydrophilic extractives in bark and wood samples of black locust (Robinia pseudoacacia L.). The radial and axial variability of hydrophilic extractives and individual compounds was also investigated within the trees. In addition to intact stem samples that included sapwood, heartwood and knots, a sample of wounded stem was included in the research in order to evaluate the contribution of traumatic structure to the variability of extractives and to examine the content of extractives in compartmentalization tissues that are formed after wounding.

\footnotetext{
* Corresponding author; e-mail: viljem.vek@bf.uni-lj.si
} 
Variability in content of hydrophilic extractives and individual phenolic compounds in black locust STEM

\section{MATERIALS AND METHODS}

\subsection{SAMPLING OF BLACK LOCUST TREES}

Bark and wood samples of six adult black locust (Robinia pseudoacacia L.) trees felled at the end of January 2016 in a suburban forest $\left(445^{\circ} 56^{\prime} 46.8^{\prime \prime} \mathrm{N} 13^{\circ} 40^{\prime} 05.1^{\prime \prime} \mathrm{E}\right)$ were included in the present investigation. The sample trees were on average $22 \mathrm{~m}$ high, with a diameter of $26 \mathrm{~cm}$ at breast height (Vek et al. 2019). Four stem disks were sawn from each felled tree at $0.20 \mathrm{~m}, 3.30 \mathrm{~m}, 6.40 \mathrm{~m}$, and $9.50 \mathrm{~m}$. Discs containing knotwood $(\mathrm{KW})$ were sampled in the crowns of the harvested trees.

After the sample discs had been air dried for a month, a radial profile of stem wood was obtained by taking an oriented series of samples in a direction from the periphery towards the pith (Fig. 1). One sample of bark (B), one sample of sapwood (SW) and several samples of heartwood (HW) were taken from each of the sampled stem discs. Heartwood was sampled according to the age of samples (number of annual rings). The youngest outermost heartwood sample was marked HW1 and the oldest sample near the pith HW5 (Fig. 1). Because some of the stems had been injured, wound-associated wood was also sampled. The reaction zone (RZ), wound-wood (WW) and discoloured and/or decayed wood (DW) were sampled as already described (Vek et al. 2014).

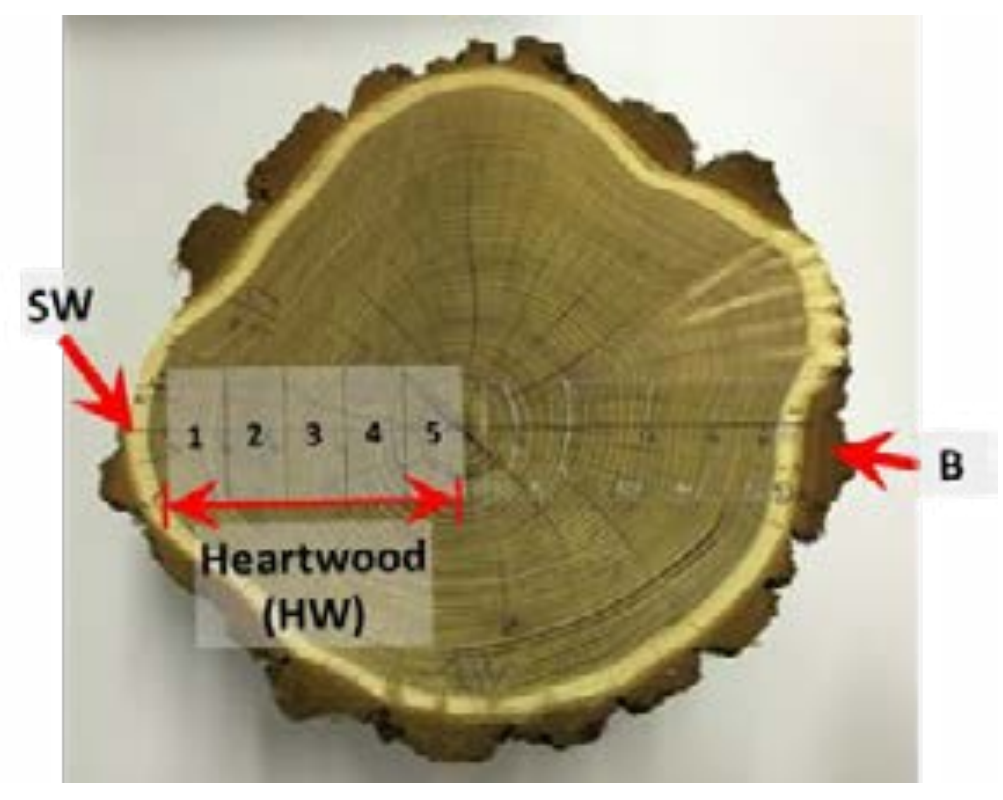

Figure 1: Stem disc of black locust (Robinia pseudoacacia L.).

All sample discs were visually inspected and the position of sampling was defined (Fig. 1). The age of samples was estimated by counting the annual growth rings. More than 170 samples of black locust were prepared for the purposes of the study. Following overnight oven drying at $50{ }^{\circ} \mathrm{C}$, wood blocks were disintegrated with a Retsch SM 2000 cutting mill using a $1 \mathrm{~mm}$ bottom sieve. The wood meal was placed in sealed bottles and stored in a dark and cold place until further analysis.

\subsection{EXTRACTION OF BARK AND WOOD SAMPLES}

Before extraction, the bark and wood samples of black locust were freeze-dried in a Telstar LyoQuest lyophylizator at 0.040 mbar and $-82{ }^{\circ} \mathrm{C}$, to a constant mass. Extraction of the dried material was done in a Soxhlet apparatus with $90 \%$ acetone (aq, v/v) for 6 hours at $110^{\circ} \mathrm{C}$, according to the protocol described in Vek et al. (2019). All the extracts were transferred into amber-coloured bottles and stored in a freezer at $-25{ }^{\circ} \mathrm{C}$.

\subsection{CHEMICAL ANALYSIS OF BLACK LOCUST EXTRACTIVES}

The content of hydrophilic extractives was measured gravimetrically by drying $10 \mathrm{ml}$ of wood extract to a constant mass (mg/g dw). 
Variability in content of hydrophilic extractives and individual phenolic compounds in black locust STEM

Total phenols were measured according to a protocol similar to those already described (Scalbert et al. 1989; Singleton and Rossi 1965; Vek et al. 2013; Vek et al. 2014). However, diluted 2N Folin-Ciocalteu's phenol reagent (aq) and an aqueous solution of sodium carbonate $(75 \mathrm{~g} / 1)$ were added to each wood extract. The reaction was performed in a $4.5 \mathrm{ml}$ disposable macro cell closed with a $10 \times 10 \mathrm{~mm}$ polyethylene lid. After incubation of the reaction mixtures, the absorbance was measured at $765 \mathrm{~nm}$ by Perkin-Elmer Lambda UV-Vis. Gallic acid was used as a reference for semi-quantitative and relative evaluation of total phenols. The results were determined by the standard curve of gallic acid (concentration range between $0 \mathrm{mg} / \mathrm{l}$ and $500 \mathrm{mg} / \mathrm{l}$ ) and expressed in milligrams of gallic acid equivalents per gram of dried wood sample (mg GAE/g).

Detailed information on chemical identities and quantities of compounds was obtained by high performance liquid chromatography (HPLC). Chromatographic analysis was performed on the Thermo Scientific Accela HPLC system. The HPLC had a quarter 600 pump and a photodiode array detector (PDA). Separation of samples was done on a Thermo Accucore C18 column (4.6 ID $\times 150 \mathrm{~mm}, 2.6 \mu \mathrm{m})$. Water (A) and methanol (B), both containing $0.1 \%$ of formic acid, served as a mobile phase. The flow rate of the mobile phase was set at $1000 \mu \mathrm{l} / \mathrm{min}$. The gradient used was $5-95 \%$ of solvent (B). Both the auto-sampler containing sample trays and the column oven were thermostated, at $5{ }^{\circ} \mathrm{C}$ and $30{ }^{\circ} \mathrm{C}$, respectively. Three microliters of wood extract were injected into the column for each HPLC run. Absorbance was measured at $280 \mathrm{~nm}$ and UV spectra were recorded from $200 \mathrm{~nm}$ to $400 \mathrm{~nm}$. Robinetin (Rob) was also qualitatively checked at $363 \mathrm{~nm}$, which gave a maximum absorption for Rob. Peak identities were investigated by comparison of retention times and UV spectra of separated compounds with those of analytical standards. Dihydrorobinetin (DHR), Rob and piceatannol (PT) were identified and quantified. The samples were measured in triplicate. The contents were expressed in milligrams of dihydrorobinetin (DHR) and robinetin (Rob) per gram of dry wood $(\mathrm{mg} / \mathrm{g} \mathrm{dw})$. The chromatographic method was linear in the selected concentration range $\left(R^{2} \geq 0.99\right)$.

\subsection{STATISTICS}

Basic statistical analysis was performed with Statgraphics software. The data were first checked for normal distribution, and analysis of variance (ANOVA) and Fisher's least significant difference (LSD) procedure at a 95.0\% confidence level were performed. Structural formulas of compounds were prepared with Perkin Elmer's ChemDraw software.

\section{RESULTS AND DISCUSSION}

\subsection{QUALI- AND QUANTITATIVE COMPOSITION OF BARK AND WOOD EXTRACTS OF BLACK LOCUST}

Extraction of bark and wood samples gave comparable amounts of hydrophilic extractives (HE) (ANOVA, p = 0.076). Extraction of more than one hundred samples showed HW of black locust to contain an average of $6.05 \%$ (w/w $\mathrm{dw}$ ) of hydrophilic extractives (HE). In contrast to Sablik et al. (2016), the HW of trees investigated in our study contained larger amounts of HE than bark (B) samples. Knotwood (KW) and heartwood (HW) samples contained higher contents of HE than did bark (B) and sapwood (SW) (Fig. 2) (LSD test). The relatively large amount of HE in SW samples can be explained by the presence of non-structural storage carbohydrates in sapwood (Höll 1972; Magel et al. 1994). 


\section{Variability in content of hydrophilic extractives and individual phenolic compounds in black locust STEM}

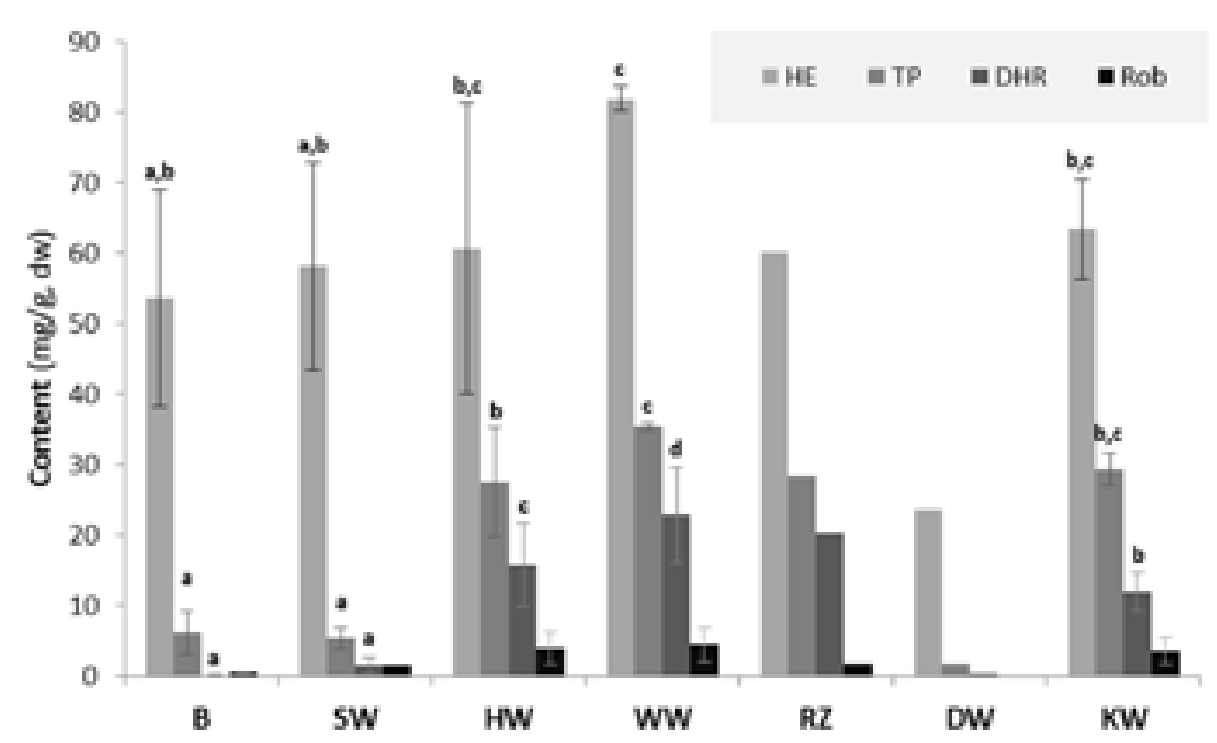

Figure 2: Content of hydrophilic extractives (HE), total phenols (TP), dihydrorobinetin (DHR) and robinetin (Rob) in bark and wood samples of black locust (Robinia pseudoacacia $\mathrm{L}$.). $\mathrm{B}=$ bark; $\mathrm{SW}=$ sapwood; HW = heartwood; WW = wound-wood; RZ = reaction zone; $\mathrm{DW}=$ decayed wood; $\mathrm{KW}=$ knotwood. $^{\mathrm{a}-\mathrm{d}}$, different letters on the error bars of the same series of columns indicate statistically significant differences at a $95 \%$ confidence level (LSD test).

Spectrophotometric analysis revealed significant differences in total phenols (TP) among the studied samples of black locust (ANOVA, p TP $<0.001$, p DHR < 0.001) (Fig. 2), while HPLC analysis confirmed DHR to be the dominant and characteristic compound of wood extracts of black locust (Fig. 2), accompanied by the presence of low amounts of Rob and PT. Chromatographic analysis revealed significant differences in the content of DHR among the studied samples of black locust (ANOVA, p TP $<0.001$, p DHR $<0.001$ ) (Fig. 2). The largest contents of Rob were measured in HW $(3.9 \pm 2.30 \mathrm{mg} / \mathrm{g})$ and KW $(3.4 \mathrm{mg} \pm 1.88)$ extracts. However, the content of Rob was excluded from statistical analysis since the measured values were not normally distributed. The data were positively skewed, meaning that low Rob contents occurred more often than would be expected with a normal distribution. A skewed distribution of the concentrations of phenolic extractives in heartwood samples of Scots pine (Pinus sylvestris L.) was also reported by Harju and Venäläinen (2006).

Among the samples of intact stems (B, SW, HW, KW), the highest amounts of phenolic extractives (TP) and DHR were characteristic of HW and KW samples (LSD test) (Fig. 2). Significantly lower amounts were measured in B and SW (Fig. 2). Analysis of SW revealed the presence of DHR only. Only B extracts contained piceatannol (PT) in addition to DHR and small amounts of Rob. On average, $60.5 \pm 20.6 \mathrm{mg} / \mathrm{g}$ of HE, $27.5 \pm 7.62 \mathrm{mg} / \mathrm{g}$ of TP, $15.7 \pm 5.87$ $\mathrm{mg} / \mathrm{g}$ of DHR, and $3.9 \pm 2.30 \mathrm{mg} / \mathrm{g}$ of Rob were measured in the HW samples. Compared to SW samples, the amounts of DHR and Rob in HW extracts were 10.5- and 2.7-times larger. These results confirm the findings of other research groups that have reported the chemical composition of extractives in wood of black locust (Bostyn et al. 2018; Magel et al. 1994; Reinprecht et al. 2010; Sablik et al. 2016). Slightly higher amounts of DHR and Rob were mentioned in the reports of Sanz et al. $(2011 ; 2012 b)$.

HW samples contained significantly larger amounts of DHR than did KW samples (LSD test) (Fig. 2). On the other hand, KW contained significantly larger amounts of phenolic compounds than B, SW and HW (LSD test) (Fig. 2). Compared to the stemwood samples of black locust, the relative contents of extractives in KW were not as high as has been reported for coniferous knotwood, in which knots contained more than hundreds of times more phenolic extractives than heartwood of the same tree (Willför et al. 2003a; Willför et al. 2003b; Willför et al. 2004).

The presence of DHR in bark samples of black locust has already been reported by other research groups (Magel et al. 1994), whereas the presence of PT in bark extract is reported here for the first time. It was reported that larger amounts of B extractives than obtained in our study can be gained by extracting bark of black locust with a mixture of methanol and water (Sablik et al. 2016). PT and resveratrol were identified at a significant concentration in mature heartwood of black locus by Sergent et al. (2014), but this was not confirmed by our chromatographic analysis. In addition to flavonoids, bark of trees can contain polyphenols of higher molecular mass, i.e., condensed tannins (Holmbom 2011; Smith et al. 1989). Oligomers of condensed tannins containing robinetinidol, i.e., prorobinetinidins, 
Variability in content of hydrophilic extractives and individual phenolic compounds in black locust STEM

have also already been reported for seasoned HW of black locust (Sanz et al. 2012a; Sanz et al. 2011). These compounds were not recovered from the samples with the extraction procedure applied in our study.

\subsection{VARIABILITY OF EXTRACTIVES WITHIN TREES}

Table 1 shows the distribution of extractives along the black locust stems in HW only. Our investigation showed an absence of significant vertical variation in the average amounts of HE, TP and DHR along the stems of the investigated trees (ANOVA; p HE $>0.050, \mathrm{p}$ TP $>0.050$, p DHR > 0.050) (Table 1). In spite of the ANOVA results, a clear decrease of the DHR content with increasing height of the HW sampling can be read from Table 1. Our investigation showed that the HW disc samples taken at $0.2 \mathrm{~m}$ had significantly larger DHR contents than samples taken at $9.5 \mathrm{~m}$ (Table 1) (LSD test). Similar findings for HE were reported for B by Adamopoulos et al. (2005), but the authors extracted larger amounts of HE from the HW samples from a tree top (Adamopoulos et al. 2005).

Table 1: Contents of hydrophilic extractives, total phenols and dihydrorobinetin in heartwood (HW) samples of black locust (Robinia pseudoacacia L.). Discs containing heartwood samples were taken at $0.2 \mathrm{~m}, 3.3 \mathrm{~m}, 6.4 \mathrm{~m}$ and $9.5 \mathrm{~m}$ above the ground.

\begin{tabular}{|c|c|c|c|c|c|c|}
\hline \multirow[t]{2}{*}{$\begin{array}{c}\text { Sampling } \\
\text { height }\end{array}$} & \multicolumn{2}{|c|}{$\begin{array}{c}\text { Hydrophilic extractives } \\
\text { (mg/g dw) }\end{array}$} & \multicolumn{2}{|c|}{$\begin{array}{l}\text { Total phenols } \\
\text { (mg GAE/g dw) }\end{array}$} & \multicolumn{2}{|c|}{$\begin{array}{l}\text { Dihydrorobinetin } \\
\qquad(\mathrm{mg} / \mathrm{g} \mathrm{dw})\end{array}$} \\
\hline & avg & $S D$ & avg & $S D$ & avg & $S D$ \\
\hline 0.2 & $62.1^{a}$ & 25.14 & $28.9^{a}$ & 8.14 & $18.4^{b}$ & 7.41 \\
\hline 3.3 & $57.0^{\mathrm{a}}$ & 19.89 & $26.4^{\mathbf{a , b}}$ & 8.23 & $15.6^{\mathrm{a}, \mathrm{b}}$ & 5.50 \\
\hline 6.4 & $64.9^{\mathrm{a}}$ & 19.91 & $28.1^{\mathbf{a}, \mathbf{b}}$ & 8.25 & $15.7^{\mathbf{a}, \mathbf{b}}$ & 5.13 \\
\hline 9.5 & $57.6^{\mathrm{a}}$ & 16.25 & $27.5^{\mathbf{a}, \mathbf{b}}$ & 5.26 & $14.1^{\mathrm{a}}$ & 5.03 \\
\hline
\end{tabular}

(Fisher's least significant difference (LSD) procedure).

The content of hydrophilic extractives was highest in the younger part of the heartwood. The extracts of older parts of heartwood (HW4 and HW5) had comparable HE concentrations as B and SW samples (LSD test). In comparison to the oldest HW5 samples, significantly more HE was extracted from B and SW. Significant differences in the content of HE, total phenols and DHR were found for the HW samples of the radial series (ANOVA, $p$ HE $<0.001, p$ TP $<0.001$, $p$ DHR $<0.001$ ). The LSD test showed that the youngest heartwood (HW1) contained significantly higher amounts of hydrophilic extractives, total phenols and DHR than older parts (HW2, HW3, HW4, and HW5). This is in contrast to Magel et al. (1994), who found that DHR augmented within the heartwood up to a more or less constant level irrespective of the sampling season. On the other hand, maximum values of Rob have been shown to be characteristic of older parts of HW (Magel et al. 1994). The relatively regular distribution of phenolic compounds in HW observed in our study could hardly be explained solely by variation in the content of non-structural carbohydrates at the sapwood-heartwood boundary, which are considered to be a major source of heartwood compounds in black locust (Magel et al. 1994; 1991). We assume that the smaller content of phenolic extractives from the HW samples in the inner parts of a black locust stem can be explained by the phenolics being chemically bonded to the cell wall and being therefore not extractable with the extraction conditions used in this study. This is in accordance with UV microspectrophotometry results showing a higher content of flavonoids deposited in the walls of cells in mature (inner) HW than in juvenile (outer) HW (Dünisch et al. 2010).

\subsection{EXTRACTIVES IN TRAUMATIC WOOD STRUCTURES}

The phytochemical profile of wound associated wood tissues differed from that of intact stemwood. The highest amounts of HE were found in wound-wood (WW), which is formed because of stem injury (LSD test). Chemical analysis revealed that WW contained $81.8 \pm 1.72 \mathrm{mg}$ of HE, $35.3 \pm 0.55 \mathrm{mg} / \mathrm{g}$ of total phenols, $22.8 \pm 6.75 \mathrm{mg} / \mathrm{g}$ of DHR and $4.5 \pm 2.36 \mathrm{mg} / \mathrm{g}$ of Rob (Fig. 2). It is assumed that the higher content of HE and TP in WW than in intact SW and HW can be explained by the two-stage process, which involves WW formation and therefore transformation of WW to HW. This observation indicates that DHR may be classified as phytoalexin (Hart and Shrimpton 1979; Pearce 1990; Sergent et al. 2014), although furthers studies are needed to confirm this speculation.

The lowest concentrations of HE were measured in decayed wood (DW) (LSD test) (Fig. 2). Lower amounts of extractives and the absence of DHR and Rob in DW can be explained by fungal degradation of flavonoids. The reaction 
Variability in content of hydrophilic extractives and individual phenolic compounds in black locust STEM

zone (RZ) was a narrow and darkly coloured morphological barrier that separated heartwood from decayed parts in a stem, contained significantly larger amounts of quantified hydrophilic extractives than DW and higher amount of DHR than unaffected HW. These results support the finding (Vek et al. 2014) that traumatic tissues formed in wood contribute to the variability of extractive content within a tree.

\section{Conclusion}

The results of the study indicate a significant radial and less pronounced axial variability in the amounts of extractives in intact stem tissues of black locust (Robinia pseudoacacia L.). The highest contents of hydrophilic extractives, total phenols, dihydrorobinetin and robinetin were characteristic of heartwood. Lowest amounts of hydrophilic extractives were extracted from sapwood and bark. Examination of extractives content along the trees revealed that the content of DHR decreases acropetally.

\section{ACKNOWLEDGEMENTS}

The authors would like to thank Urban Innovative Actions (project Applause, UIA02-228) and the Slovenian Research Agency for financial support of program P4-0015. Many thanks also to Mrs. Helena Zorn and Mr. Miloš Mervič, both from the Slovenia Forest Service (Tolmin Regional Unit), for providing professional assistance with collecting the material, and to Mr. Martin Cregeen for language editing. The guideline and template has been kindly provided for use by the International Scientific Conference on Hardwood Processing - ISCHP2019.

\section{REFERENCES}

Adamopoulos S, Voulgaridis E, Passialis C (2005) Variation of certain chemical properties within the stemwood of black locust (Robinia pseudoacacia L.) Holz Roh-Werkst 63:327-333.

Bostyn S, Destandau E, Charpentier J-P, Serrano V, Seigneuret J-M, Breton C (2018) Optimization and kinetic modelling of robinetin and dihydrorobinetin extraction from Robinia pseudoacacia wood Ind Crops Prod 126:22-30.

Dünisch O, Richter HG, Koch G (2010) Wood properties of juvenile and mature heartwood in Robinia pseudoacacia L Wood Sci Technol 44:301-313.

Harju AM, Venäläinen M (2006) Measuring the decay resistance of Scots pine heartwood indirectly by the Folin-Ciocalteu assay Can J For Res 36:1797-1804

Hart JH, Shrimpton DM (1979) Role of stilbenes in resistance of wood to decay Phytopathology 69:1138-1143.

Höll W (1972) Starke und Starkeenzyme im Holz van Robinia pseudoacacia L. Holzforschung 26:41-45.

Holmbom B (2011) Extraction and utilisation of non-structural wood and bark components. In: Alén R (ed) Biorefining of forest resources. vol book 20. Paper Engineers' Association/Paperi ja Puu Oy, Helsinki, pp 178-224.

Latorraca JVF, Dunisch $O$, Koch $G$ (2011) Chemical composition and natural durability of juvenile and mature heartwood of Robinia pseudoacacia L. Anais Da Academia Brasileira De Ciencias 83:1059-1068.

Magel E, Jayallemand C, Ziegler H (1994) Formation of heartwood substances in the stemwood of Robinia pseudoacacia L. II. Distribution of nonstructural carbohydrates and wood extractives across the trunk Trees-Struct Funct 8:165-171.

Magel EA, Drouet A, Claudot AC, Ziegler H (1991) Formation of heartwood substances in the stem of Robinia pseudoacacia L. I. Distribution of phenylalanine ammonium lyase and chalcone synthase across the trunk Trees-Struct Funct 5:203-207.

Pearce RB (1990) Occurrence of decay-associated xylem suberization in a range of woody species Eur J Plant Pathol 20:275-289

Reinprecht L, Zubkova G, Marchal R (2010) Decay resistance of laminated veneer lumbers from black locust wood Wood research 55:39-52.

Sablik P, Giagli K, Paril P, Baar J, Rademacher P (2016) Impact of extractive chemical compounds from durable wood species on fungal decay after impregnation of nondurable wood species Eur J Wood Wood Prod 74:231-236.

Sachsse H (1984) Einheimische nutzhölzer und ihre bestimmung nach makroskopischen merkmalen. Verlag Pul Parey, Hamburg, Berlin

Sanz M, de Simon BF, Cadahia E, Esteruelas E, Munoz AM, Hernandez MT, Estrella I (2012a) Polyphenolic profile as a useful tool to identify the wood used in wine aging Analytica Chimica Acta 732:33-45.

Sanz Met al. (2011) Effect of toasting intensity at cooperage on phenolic compounds in acacia (Robinia pseudoacacia) heartwood J Agric Food Chem 59:3135-3145. 
Sanz M et al. (2012b) Polyphenols in red wine aged in acacia (Robinia pseudoacacia) and oak (Quercus petraea) wood barrels Analytica Chimica Acta 732:83-90.

Scalbert A, Monties B, Janin G (1989) Tannins in wood: Comparison of different estimation methods J Agric Food Chem 37:1324-1329.

Scheffer TC, Morrell JJ (1998) Natural durability of wood: A worldwide checklist of species. Oregon State University. Research Contribution 22

Sergent T, Kohnen S, Jourez B, Beauve C, Schneider YJ, Vincke C (2014) Characterization of black locust (Robinia pseudoacacia L.) heartwood extractives: identification of resveratrol and piceatannol Wood Sci Technol 48:1005-1017.

Singleton VL, Rossi JA, Jr. (1965) Colorimetry of total phenolics with phosphomolybdic-phosphotungstic acid reagents Am J Enol Vitic 16:144-158.

Smith AL, Campbell CL, Walker DB, Hanover JW (1989) Extracts from black locust as wood preservatives: Extraction of decay resistance from black locust heartwood Holzforschung 43:293-296.

Torelli N (2003) Robinija (Robinia pseudoacacia L.) in njen les Les 54:6-10.

Vek V, Oven P, Poljansek I (2013) Content of Total Phenols in Red Heart and Wound-Associated Wood in Beech (Fagus sylvatica L.) Drvna Ind 64:25-32.

Vek V, Oven P, Ters T, Poljansek I, Hinterstoisser B (2014) Extractives of mechanically wounded wood and knots in beech Holzforschung 68:529-539.

Vek V, Poljanšek I, Oven P (2019) Efficiency of three conventional methods for extraction of dihydrorobinetin and robinetin from wood of black locust Eur J Wood Wood Prod 77: 891-901 doi:10.1007/s00107-019-01430-x

Vitková M, Müllerová J, Sádlo J, Pergl J, Pyšek P (2017) Black locust (Robinia pseudoacacia) beloved and despised: A story of an invasive tree in Central Europe For Ecol Manage 384:287-302.

Willför S, Hemming J, Reunanen M, Eckerman C, Holmbom B (2003a) Lignans and lipophilic extractives in Norway spruce knots and stemwood Holzforschung 57:27-36.

Willför S, Hemming J, Reunanen M, Holmbom B (2003b) Phenolic and lipophilic extractives in Scots pine knots and stemwood Holzforschung 57:359-372.

Willför S, Nisula L, Hemming J, Reunanen M, Holmbom B (2004) Bioactive phenolic substances in industrially important tree species. Part 1: Knots and stemwood of different spruce species Holzforschung 58:335-344. 